\section{Diagnosis of small-bowel metastasis of malignant pleural mesothelioma by capsule endoscopy and double ballon enteroscopy}

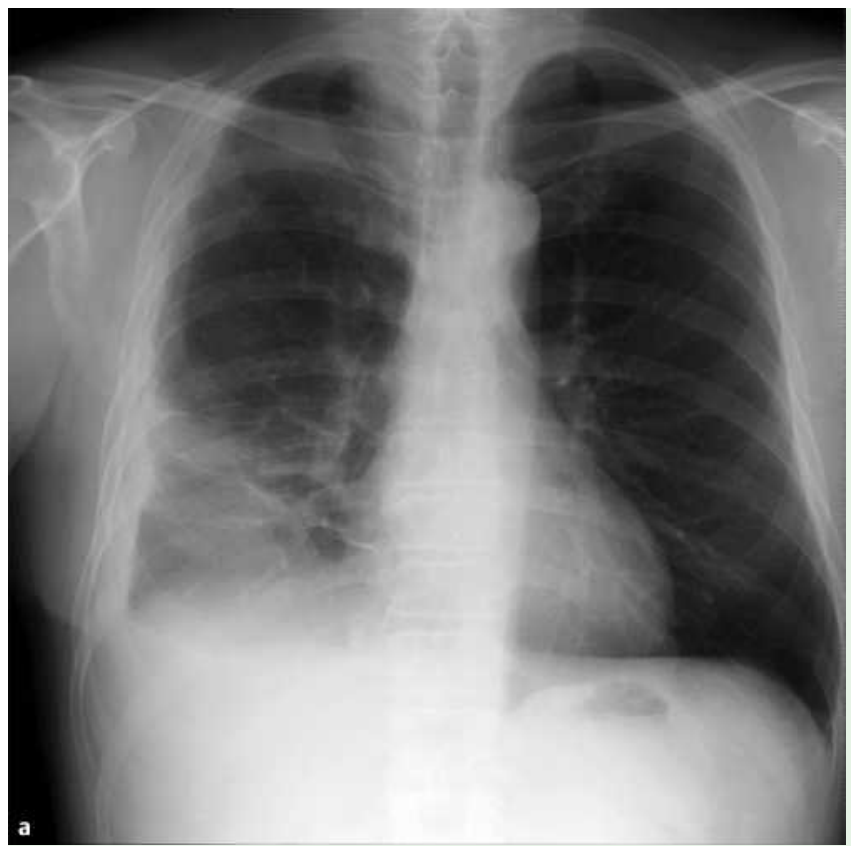

Fig. 1 a A chest radiograph showing right-sided pleural thickening and a pleural effusion. $\mathbf{b}$ A computed tomographic scan of the chest showed diffuse pleural thickening of the right hemithorax.

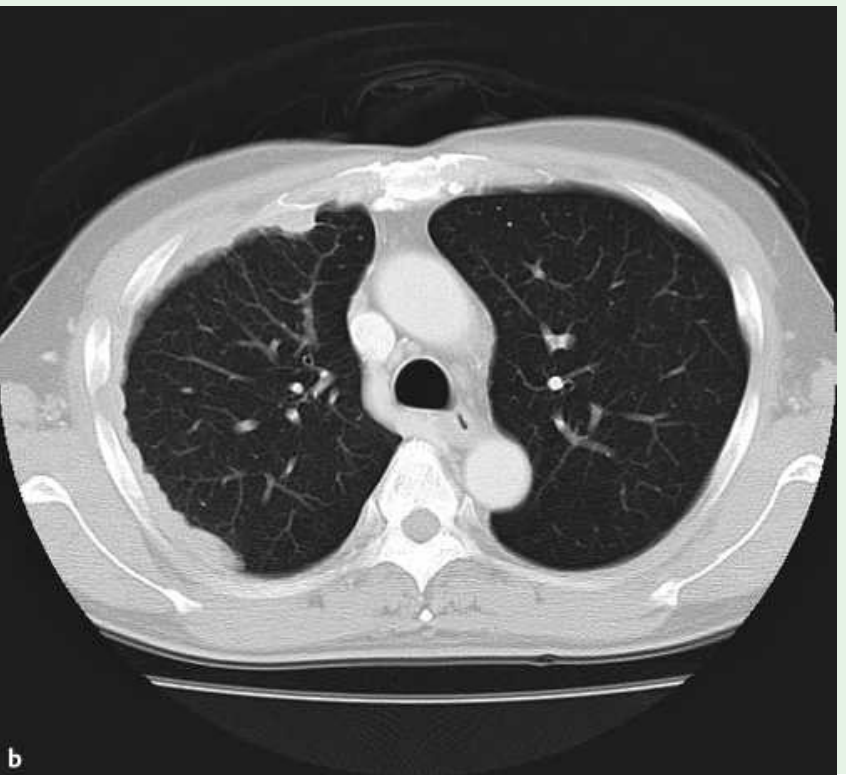

A 62-year-old man who was diagnosed with malignant pleural mesothelioma ( $\bullet$ Fig. 1) underwent right extrapleural pneumonectomy. He was followed up with chest radiographs, computed tomographic scans, and laboratory investigations, none of which showed any findings. Nine months later, he was readmitted for the investigation of tarry stools and iron deficiency anemia. Esophagogastroduodenoscopy, total colonoscopy, red blood
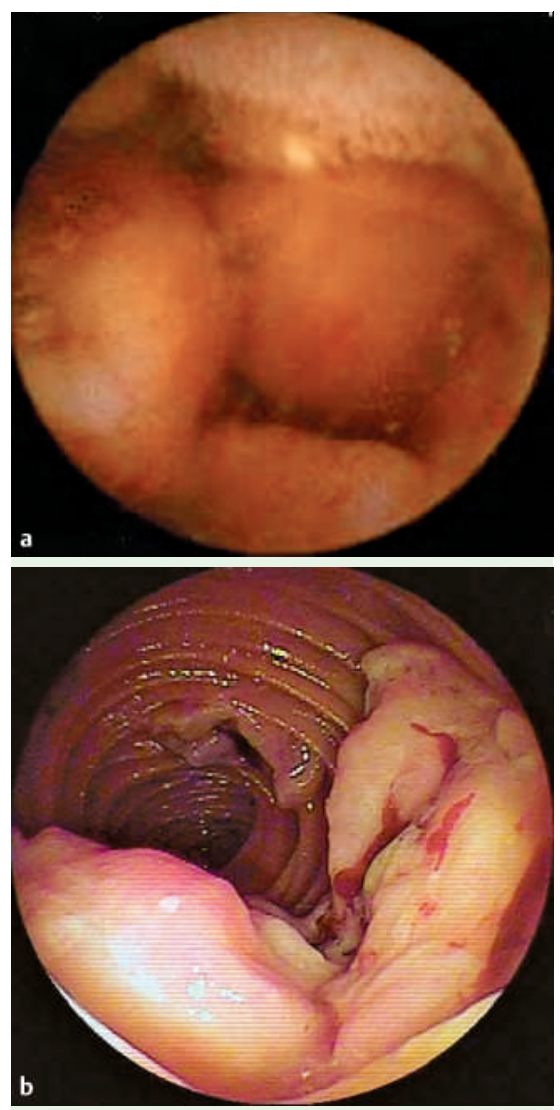

Fig. 2 a Video capsule endoscopy revealed multiple protruding lesions with slight but continuous oozing, and these were found from the proximal jejunum to the terminal ileum. b Multiple protruding lesions measuring 20 $30 \mathrm{~mm}$ were clearly shown by double-balloon enteroscopy. These protrusions were covered with normal mucosa, with central ulceration and evidence of mild bleeding.

mens showed these protusions to contain tumor cells which ranged in appearance from large polyhedral cells to spindleshaped cells ( Fig. 3 a). Immunohistochemical examination revealed tumor cells positive for the mesothelial markers, calretinin and WT1 ( Fig. $\mathbf{3 b}$ ), and the protrusions were diagnosed as metastatic malignant mesothelioma of the small bowel.

Malignant pleural mesothelioma is an aggressive tumor and its incidence has increased significantly in recent years [1]. Small-bowel metastasis from malignant pleural mesothelioma has never been reported before, so this apparently is the first case. Furthermore, we obtained clear endoscopic images of the lesions while the patient was still alive.

Some patients with gastrointestinal bleeding remain undiagnosed even after upper endoscopy and total colonoscopy [2], and most of these patients will have bleeding sites in the small bowel. Video 


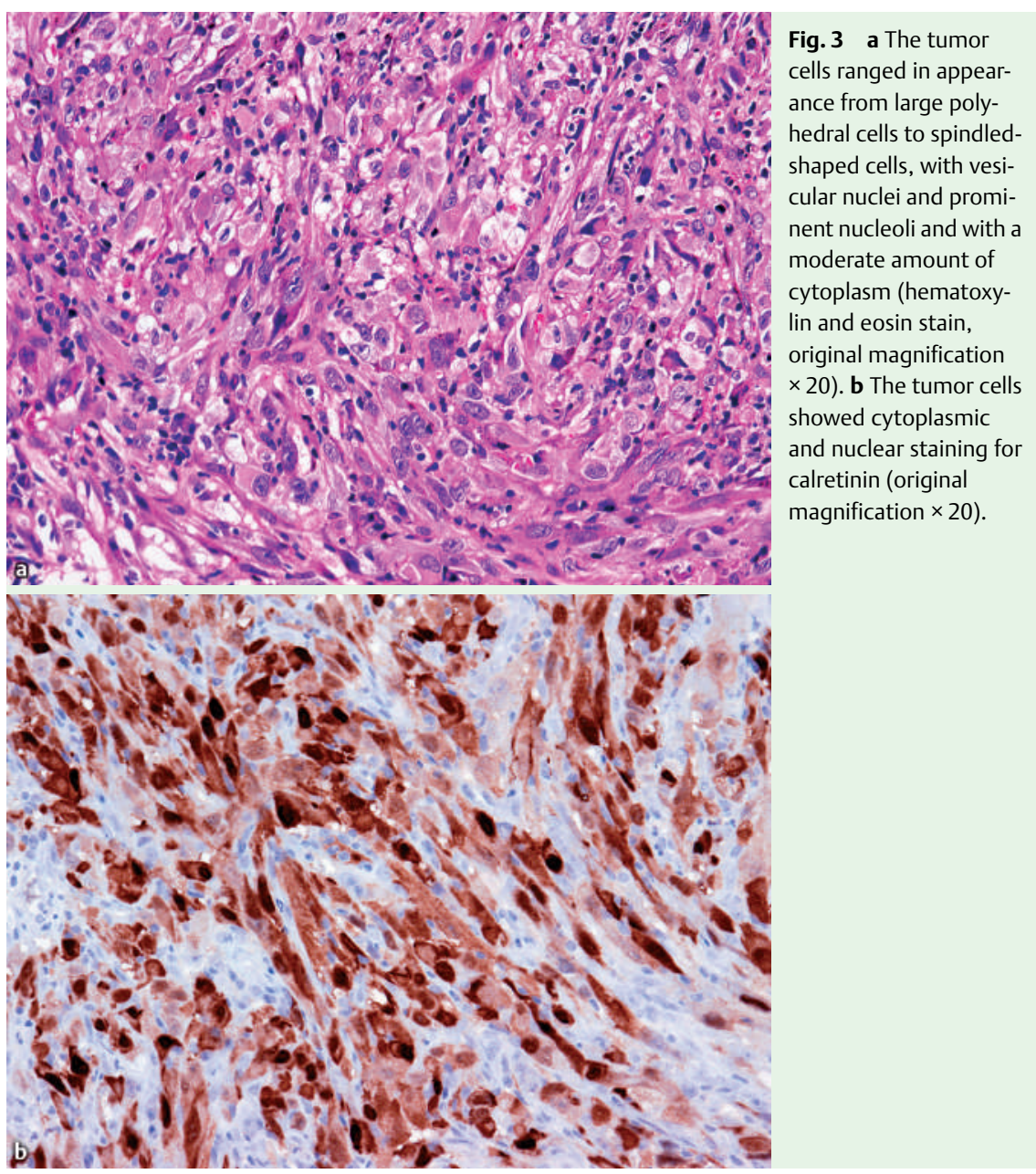

capsule endoscopy and double-balloon enteroscopy have been introduced recently for the evaluation of the small bowel. Iddan et al. [3] were the the first to report on capsule endoscopy and it is now widely accepted as an investigation for small-intestinal screening. Even trivial bleeding was detected in this case by capsule endoscopy, although red blood cell scintigraphy had failed to detect its source. A similar result was confirmed previously by Hartmann et al. [4]. Double-balloon enteroscopy, which was developed by Yamamoto et al. [5], enabled us to obtain biopsy specimens, which circumvented a limitation of capsule endoscopy. The combination of capsule endoscopy and double-balloon enteroscopy contributed significantly to our reaching a diagnosis in this case.

Endoscopy_UCTN_Code_CCL_1AC_2AC
Y. Kakugawa', S. Watanabe'2,

N. Kobayashi ${ }^{3}$, M. Tani ${ }^{1}$, S. Tanaka ${ }^{4}$,

K. Tsuta ${ }^{5}$, D. Saito ${ }^{1}$

${ }^{1}$ Endoscopy Division, National Cancer

Center Hospital, Tokyo, Japan

2 Thoracic Surgery Division, National Cancer Center Hospital, Tokyo, Japan

3 Department of Diagnostic Imaging, Tochigi Cancer Center Hospital, Tochigi, Japan

${ }^{4}$ Third Department of Internal Medicine, Nippon Medical School, Tokyo, Japan

${ }^{5}$ Clinical Laboratory Division, National Cancer Center Hospital, Tokyo, Japan

\section{References}

1 Robinson BW, Lake RA. Advances in malignant mesothelioma. N Engl J Med 2005; 353: 1591 - 1603

2 Hayat M, Axon AT, O'Mahony S. Diagnostic yield and effect on clinical outcomes of push enteroscopy in suspected small-bowel bleeding. Endoscopy 2000; 32: 369- 372

3 Iddan G, Meron G, Glukhovsky A et al. Wireless capsule endoscopy. Nature 2000; 405: 417

4 Hartmann D, Schilling D, Bolz G et al. Capsule endoscopy versus push enteroscopy in patients with occult gastrointestinal bleeding. Z Gastroenterol 2003; 41: 377-382

5 Yamamoto H, Sekine Y, Sato Y et al. Total enteroscopy with a nonsurgical steerable double-balloon method. Gastrointest Endosc 2001; 53: 216-220

Bibliography

DOI 10.1055/s-2007-966546

Endoscopy 2007; 39: E229-E230

(c) Georg Thieme Verlag KG Stuttgart · New York . ISSN 0013-726X

Corresponding author

Y. Kakugawa, MD

Endoscopy Division

National Cancer Center Hospital

5-1-1 Tsukiji

Chuo-ku

Tokyo 104-0045

Japan

Fax: +81-3-3542-3815

yakakuga@ncc.go.jp 